\title{
IDÉIAS
}

\section{Algumas reflexões sobre Reforma Administrativa}

\author{
Hermano Machado Ferreira Lima (*)
}

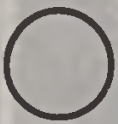

Plano de Reforma da Administração Federal, instituído pelo Governo Sarney, surgiu num contexto especifico da vida brasileira. Após um longo período de governos autoritários, viu-se, a Nação como um todo, diante de uma circunstância de impossibilidade de continuar vivenciando práticas não condizentes com os anseios daqueles que a constituem. Os mais diversificados grupos e camadas socia is nåo escondiam suas insatisfaçðes diante da condução dos destinos do Brasil. Do banqueiro ao trabalhador, do político ao intelectual, os números de insatisfeitos aumentava a cada instante.

Assim, o momento que ora vivemos não surgiu do nada mas reflete exatamente todo um contexto social específico em que os reclamos das organizações oposicionistas que souberam, na ocasião propicia, canalizar as insatisfaçoes para oferecer à Nação um momento de decisão que podemos tomar como marco, foi a eleição de Tancredo/Sarney para a Presidência da República. O que sintetiza a ocasião é sem dúvida o desejo espontâneo, instintivo, corporificado no "Mudanças Jä". Talvez possa parecer, a alguns, uma visão um tanto ingênua esta afirmativa. Como um simples "slogan", seria capaz de dar conta da complexidade dos interesses e conflitos em uma sociedade como a nossa? Sim certamente, os que assim a lerem:terão sua parcela de razão, mas, se nos dermos conta do que ocorreu no Brasil daquele instante, se nos aprofundarmos um pouco mais e tentar-

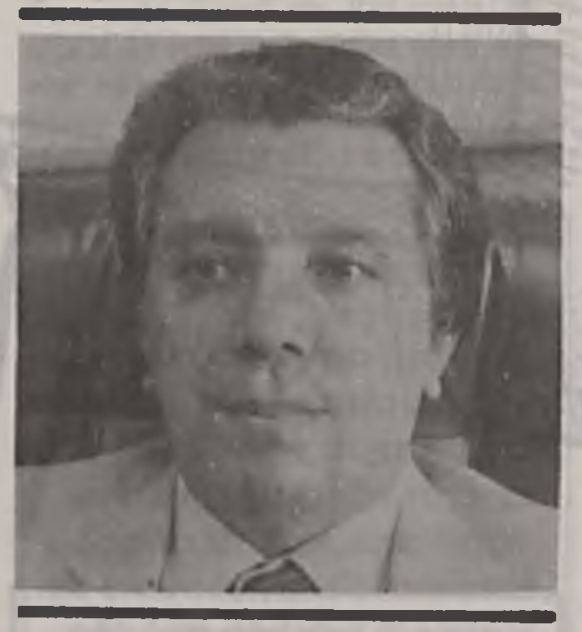

mos estabelecer um paralelo entre o momento da eleiçao de Tancredo/Sarney e o agora, veremos que nada mais dá corpo e sintetiza o descjo da Nação do que a reivindicacilo por mudanças. E é no bojo destc contexto, neste amálgama de questionamentos que se inscreve a Reforma da Administração Federal.

Nesta Revista do Serviço Público, alguns já nos chamaram a atenção para o fato de que esta é a primeira vez que se faz uma Reforma Administrativa sem ser sob a égide de um regime autoritário. O Estado novo impôs sua reforma e o regime autoritário de 64 fez a sua. Têm razão. Mas este é apenas um lado da questão. É bom lembrar que reformas $\mathbf{n}$ ao se fazem no vácuo. Elas refletem também o contex to sócio-politico da sociedade em geral. O processo de modernização da sociedade brasileira, instaurado pela Revoluçăo de 30 , nảo poderia deixar imune a máquina administrativa do Estado, as-

(") Diretor de Estudos e Pesqulsas da Fundaça-Centro de Formacáo do Servidor Público, Funcep sim como o processo de internacionalização da economia brasileira implementado pelo regime autoritário de 64 tinha, no Estado e em seus aparatos administrativos, um forte aliado.

O contexto de criação de um novo regime político democrático é apenas um dos ingredientes do atual momento. O desejo de mudança transcende a conjuntura política, espargindo-se por um espaço social mais abrangente. E é nesta circunstância que o Estado e sua máquina são afetados. Ou seja, os parâmetros de eficácia da Reforma Administrativa nåo podem ser fixados visualizando-se apenas seu significado ideológico mas, sobretudo, se deste se vê liberto. Aliás, nunca será demais revelarmos que a própria constituição da Comissão Coorde nadora da Reforma Administrativa já indica o caminho buscado e confirma uma primeira preocupação. $O$ fato de ela mesma ser constituida por representantes dos mais variados segmentos da sociedade a exime de compromissos ideológicos e norteia sua postura crítica e receptiva.

O processo de reforma administrativa será tanto mais eficaz quanto mais ele se dirigir e for capaz de captar esses desejos e anseios das várias camadas sociais expressos em reivindicações, solicitaçð̄es e sugestões. Sintetizando, o reordenamento da sociedade brasileira, visando padrōes democráticos, constitui-se numa das faces de uma única moeda, sendo o seu reverso exatamente o contexto de mudança que os seus segmentos constitutivos estão a exigir.

Não podemos perder de vista que o contexto de mudanças espelha o desejo de um redirecionamento da 


\section{IDÉIAS}

sociedade em busca de novos padrões de acumulação e na superação do que alguns denominaram de capitalismo selvagem, como também o anseio de participação das várias camadas nos diversos mecanismos de ação do Estado.

Não será demais lembrarmos que a transmutação do Estado autoritário em democrático dar-se-á na proporção em que os mecanismos de atuação do Estado se tornarem visiveis, não só em seu arcabouço macro-estrutural corporificado em seu ordenamento juridico, mas, sobretudo, em suas filigramas microestruturais naquilo que alguns denominaram de práticas sociais.

Aqui caberia um exemplo. Se nos detivermos no contexto de elaboração e implantação do Decreto-lei 200 , constataremos, sem muita dificuldade, o hiato entre as intenções de seus criadores e a prática de sua ex ecução. O seu inspirador maior, o ministro Hélio Beltrão, não se cansou de salientar em vários pronunciamentos, conferências, etc., o objetivo descentralizador daquele decreto-lei. No entanto, na prática, o que se viu foi um exacerbado centralismo da administração pública federal. Veja-se que desçentralização para o ministro Beltrão não era apenas um conceito ideológico e abstrato. Para ele, descentralizar a administração do governo federal significava transferir recursos para os governos estaduais e municipais através de instrumentos ágeis, como, por exemplo, os convênios. Ho$\mathrm{je}$, o que constatamos é que este mecanismo não é tão ágil assim e que, ao invés de favorecer a autonomia dos Estados e municipios, tem sido, na prática, uma forma de o governo central impor sua vontade, muitas vezes contrariando os interesses particulares dos demais niveis de governo, e como muitas, gerou foi um conflito entre essas esferas do poder e as camadas sociais a eles mais próximo.

É verdade que o Decreto-lei 200 constitui-se hoje numa peça juridica das mais importantes para a administração pública, por seu nivel de abrangência, por sua eficácia normativa e, sobretudo, por seus aspeclos modernizadores. No entanto, a prática de sua implantação, a sua aplicação no dia-a-dia do serviço público o transfiguraram num ins-

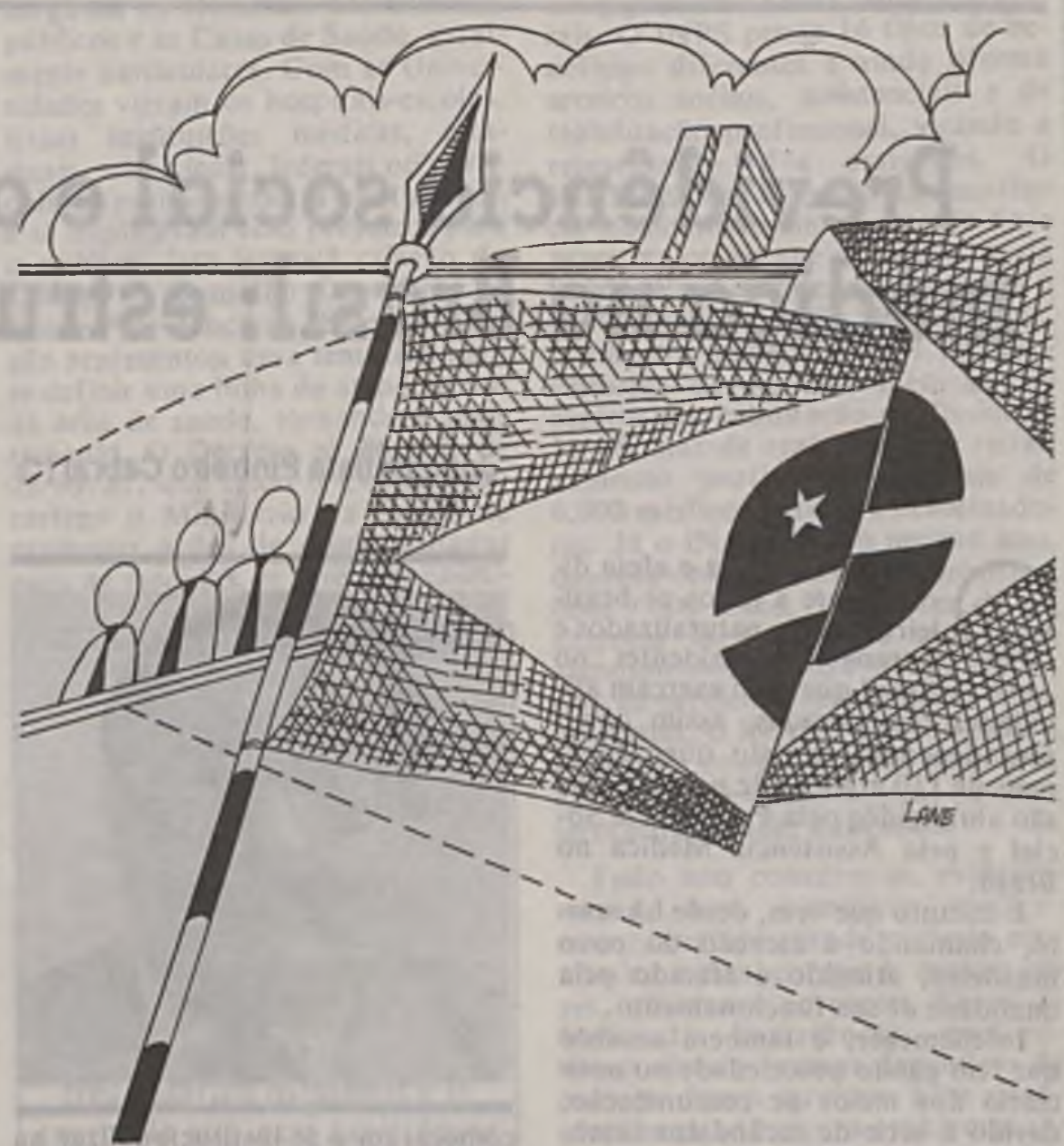

voltar nossa preocupação para dois aspectos simultâneos: produção iam de instrumentos normativos eficientes como o Decreto-lei 200 e simultaneamente a implantação de novos padrões de gerenciamento da coisa pública. Muito pouco nos valerão primores de peças legislativas, se nossos gerentes públicos continuarem aferrados a práticas autoritárias.

A verdadeira e eficaz mudança da administração pública federal surgirá, exatamente, da simbiose, do inter-relacionamento desses dois aspectos: o ordenamento jurídico versus prática gerencial. É preciso realizarmos um casamento tão perfeito entre ambos, de forma tal que um lado se reconheça no outro.|juridica que a inspira. Talvez estejamos querendo muito, certamente, mas este é o desafio que temos que enfrentar. E o sucesso da atual reforma administrativa será, tan to maior quanto for nossa disposição e nossa tenacidade em aceitarmos de frente e sem tergiversaçס̋es esse desafio. 